\title{
Echocardiography for the Pregnant Heart
}

\author{
Henrietta A. Afari, $M D^{1}$ \\ Esther F. Davis, MBBS, DPhil ${ }^{2}$ \\ Amy A. Sarma, $M D^{2,3, *}$
}

\author{
Address \\ ${ }^{1}$ Department of Medicine, Massachusetts General Hospital, Boston, MA, USA \\ ${ }^{2}$ Department of Medicine, Division of Cardiology, Massachusetts General Hospital, \\ Boston, MA, USA \\ ${ }^{*}, 3$ Harvard Medical School, Boston, MA, USA \\ Email: Asarma1@partners.org
}

Published online: 28 May 2021

(C) The Author(s), under exclusive licence to Springer Science+Business Media, LLC, part of Springer Nature 2021

This article is part of the Topical Collection on Reproductive Health and Cardiovascular Disease

Keywords Pregnancy · Echocardiography

\section{Abstract}

Purpose of review Pregnancy is associated with significant hemodynamic changes, making it a potentially high-risk period for women with underlying cardiovascular disease. Echocardiography remains the preferred modality for diagnosis and monitoring of pregnant women with cardiovascular disease as it is widely available and does not require radiation. This paper reviews the role of echocardiography along the continuum of pregnancy in at-risk patients, with a focus on key cardiac disease states in pregnancy.

Recent findings In the preconception stage, risk stratification scores such as CARPREG II, ZAHARA and the modified WHO remain central to counseling and planning. As such, echocardiography serves an important role in assessing the severity of pre-existing structural disease. Among women with pre-existing cardiovascular disease who become pregnant-as well as those who develop cardiovascular symptoms during pregnancy-echocardiography is a key imaging tool for assessment of hemodynamic and structural changes and is recommended as the first-line imaging modality when appropriate by both the American College of Obstetricians and Gynecologists (ACOG) and the Food and Drug Administration (FDA). However, routine screening intervals during pregnancy for various cardiac lesions are not well defined, resulting in clinical heterogeneity in care.

Summary Echocardiography is the imaging modality of choice for defining, risk stratifying, and monitoring cardiovascular changes throughout pregnancy. Once identified, at-risk patients should receive careful individual counseling and follow- 
up with a multidisciplinary team. Echocardiography serves as a widely available tool for serial monitoring of pregnant women with cardiovascular disease throughout pregnancy and the postpartum period.

\section{Introduction}

Cardiovascular disease (CVD) is a leading cause of maternal morbidity and mortality in the USA and globally [1-7]. Furthermore, maternal mortality is rising in the USA, with $41 \%$ of deaths retrospectively evaluated deemed to have been preventable [8]. While pregnancy is recognized as a time of hemodynamic stress for women with underlying cardiovascular disease, it is now also recognized that a substantial portion of pregnancyassociated cardiovascular complications are due to acquired disease, for which obesity, pre-existing diabetes, and pre-existing hypertension are significant risk factors. Beyond pregnancy, the postpartum period is one of elevated risk as far out as a year postpartum, with approximately one-third of maternal deaths occurring during this period [9].

Normal pregnancy is marked by several hemodynamic changes which occur over a compressed period of time (Fig. 1).

Maternal cardiac output rises early in pregnancy and increases in sum approximately $30-50 \%$ for singleton pregnancies [11-13, 14••, 15-17]. Estrogen contributes to plasma volume expansion, which increases approximately $40 \%$ throughout pregnancy. There is a concomitant increase in red cell mass-though to a lesser extent than plasma volume expansion-which contributes to the physiologic anemia of pregnancy. An increase in heart rate (which increases 10-20 beats per minute above pre-pregnancy values) contributes to the increase in cardiac output. Finally, systemic venous resistance (SVR) decreases due to maturation of the low resistance placental, which can result in a decrease in mean arterial pressure (MAP) in early pregnancy; the SVR nadirs at approximately 24 weeks of gestation and then gradually increases thereafter. SVR rapidly increases after delivery of the placental. Thereafter, hemodynamic shifts occur rapidly in the first 2 postpartum weeks, though full return to pre-pregnancy hemodynamics occur over the first 6 postpartum months.

Substantial overlap exists between symptoms that commonly accompany normal pregnancy and those that signal early manifestations of cardiovascular disease including hyperventilation (and associated dyspnea), anemia, weight gain, and edema [11]. As such, echocardiography is a clinically invaluable tool for the evaluation of pregnant women both in the context of underlying cardiovascular disease and those without known

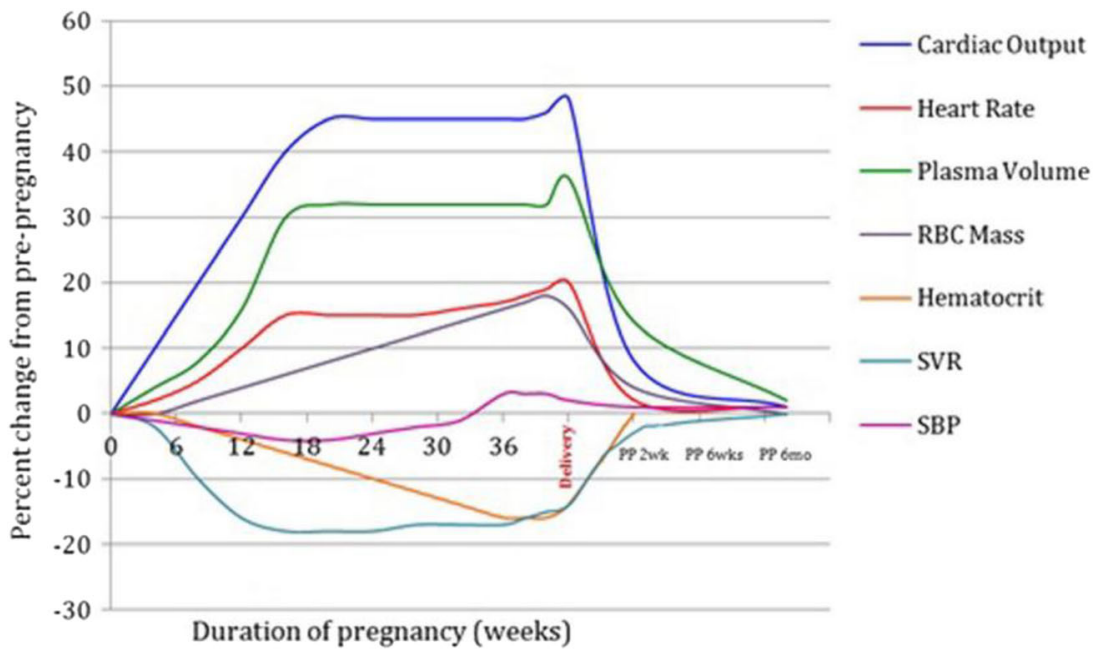

Fig. 1. Hemodynamic changes occurring in normal pregnancy. Reproduced with permission from [10]. 
pre-existing disease presenting with symptoms that are challenging to distinguish from uncomplicated pregnancy. Furthermore, it is widely available and does not require the use of radiation or intravenous contrast.

\section{Echocardiographic imaging during pregnancy}

General approaches to image acquisition for pregnant women are similar to imaging protocols utilized for non-pregnant patients. A key advantage to echocardiography in the context of pregnancy is its excellent safety profile. Investigations to date have not reported any adverse effects from the utilization of diagnostic ultrasound, which is therefore utilized frequently in clinical practice [18]. An important distinction is that supine positioning can be challenging due to compression of the inferior vena cava (IVC) and pelvic veins by the gravid uterus, particularly after 20 weeks of gestation. Left lateral decubitus positioning is therefore preferred. In late pregnancy, cardiac output is estimated to be approximately $14 \%$ lower in the supine position as compared to the left lateral decubitus position, and approximately $8 \%$ of women will experience frank symptomatic hypotension while supine [11]. When required, agitated saline contrast is generally felt to be safe during pregnancy (FDA Category B), though rigorous studies have not been performed for investigation of its use [18]. Intravenous echocardiographic contrast agents utilizing perflutren lipid microspheres or perflutren protein type A have similarly not been studied during pregnancy; as such, potential risks vs benefits must be considered with avoidance if other imaging strategies are available [19]. Where necessary, transesophageal echocardiography can be safely performed in pregnant women, with the majority of risk related to required sedation, which carries the potential for

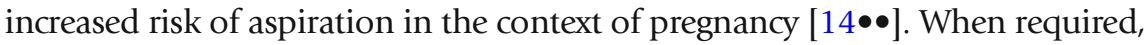

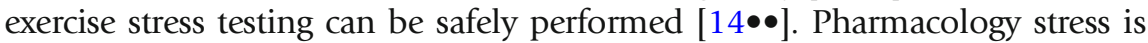
rarely indicated during pregnancy and use of pharmacologic stress agents should be avoided if possible $[14 \bullet \bullet]$.

\section{Normal echocardiographic changes in pregnancy}

The hemodynamic changes of pregnancy are often accompanied by normative structural adaptations. Echocardiographic findings of normal pregnancy are summarized in Table 1. Increases in blood volume can result in atrial and ventricular chamber dilation, though parameters remain within the upper limits of normal for non-pregnant controls [21-24]. Upper limits of normal have not been specifically defined for the pregnant woman. Reversible eccentric hypertrophy of the left ventricle is accompanied by an increase in left ventricular mass of approximately $5-10 \%$ [25]. All chamber changes typically return to baseline levels within weeks postpartum.

The effect of pregnancy on myocardial contractility is controversial. Based on conventional echocardiographic estimates, left ventricular ejection fraction (LVEF) is generally unchanged or can be slightly increased, though data to date is conflicting [13, 21-25]. Using load-independent measures-particularly tissue Doppler imaging-diastolic function similarly does not change significantly with normal pregnancy $[22,25,26]$. E/e $e^{\prime}$ remains unchanged. Due to a 
Table 1. Normal physiologic changes on echocardiography during pregnancy

\begin{tabular}{|c|c|c|}
\hline Unchanged in pregnancy & Increased in pregnancy & Normative in pregnancy \\
\hline - Ejection Fraction & - LVEDD & - Pericardial effusion (often trace to mild) \\
\hline - Fractional shortening & - LV mass & - Pseudodyskinesis \\
\hline - Peak myocardial systolic velocity & - Cardiac Output & \\
\hline - Average systolic SR & - RV diastolic area & \\
\hline$-\mathrm{E} / \mathrm{E}^{\prime}$ ratio & - LA volume & \\
\hline \multirow[t]{4}{*}{ - RVSP } & - LA size & \\
\hline & - RA size & \\
\hline & - Valvular annulus dimension & \\
\hline & - Aortic and pulmonic VTI & \\
\hline
\end{tabular}

normative decrease in pulmonary vascular capacitance, right ventricular systolic pressure (RVSP) also does not change despite substantial increases in plasma volume [25]. Pseudodyskinesis can be appreciated due to external compression from the gravid uterus.

Increase in chamber sizes and blood volumes in pregnancy can result in annular dilation, which in turn results in increased valvular regurgitation as well as increased transvalvular velocities. These effects are greatest in early third trimester and at labor and resolve early postpartum [13, 25, 27, 28]. Valvular regurgitation in pregnancy is most commonly observed in the tricuspid and pulmonic valves. Despite an increase in size of the aortic annular dimension, aortic regurgitation is not normative even in the context of pregnancy [13].

Asymptomatic pericardial effusions (often trace or mild) are common in pregnancy occurring in approximately $40 \%$ of women, in the third trimester. They are thought to be related to hormonally mediated volume retention and are most often clinically silent, resolving within 6 weeks postpartum [29].

\section{Pre-conception and echocardiography}

Because of its availability, cost-effectiveness, and versatility, echocardiography is central to the assessment of women at the pre-conception stage. The CARPREG (Cardiac Disease in Pregnancy Study) II [30••], modified WHO (World Health Organization) $[14 \bullet \bullet]$, and ZAHARA II (Zwangerschap bij Aangeboren HARtAfwijkingen [Pregnancy in Women with Congenital Heart Disease]) [31] risk stratification scores commonly utilized in clinical practice (Table 2) all incorporate severity of underlying cardiac lesion, which can and should be assessed by echocardiography prior to conception. As such, any woman with known pre-existing cardiovascular disease should undergo pre-conception echocardiography. Notably, however, the available risk scores are only applicable to women with known pre-existing cardiovascular disease and do not aid in 
Table 2. Cardiac risk factors for adverse maternal events; available risk stratification tools: CARPREG II [30], ZAHARA [31], and modified WHO [14]

\section{CARPREG II}

-Prior cardiac events or arrhythmias

-NYHA III-IV functional class or cyanosis

- Mechanical valve prosthesis

Ventricular dysfunction

-High risk left-sided valve disease/-

LVOT

-Pulmonary hypertension

- Coronary artery disease

- High-risk aortopathy

- No prior cardiac intervention first

antenatal visit $>20$ weeks gestation

\section{ZAHARA}

-Prior arrhythmia

-NYHA III-IV functional class

- Left heart obstruction (LVOT gradient $>50 \mathrm{mmHg}$,

AVA $<1 \mathrm{~cm}^{2}$ ) $\bullet$ Mechanical valve prosthesis

-Moderate-severe subpulmonic or systemic atrioventricular valvular regurgitation

- Pre-pregnancy cardiovascular medications - Cyanotic heart disease (either repaired or unrepaired)

\section{Modified WHO}

Class I: Low risk

-Mild/uncomplicated: PS, PDA,

MVP

- Repaired PDA, ASD, VSD,

anomalous pulmonary venous

drainage

-Isolated atrial/ventricular ectopic beats

Class II: Moderate risk

-Mild/uncomplicated uncorrected ASD/VSD

- Repaired TOF

- Most arrhythmias

Class II-III: Moderate-high risk

-Mild LV dysfunction

- HCM

- Valvular heart disease not

considered class I or IV

- Marfan's with a normal aortic

diameter

-Bicuspid with aortic dilation

$<45 \mathrm{~mm}$

-Repaired coarctation with

bicuspid

Class III: High risk

-Mechanical valve prosthesis

- Systemic RV

- Fontan circulation

- Unrepaired TOF

- Complex congenital heart disease

-Marfan with 40-45 mm aortic di-

lation

-Bicuspid with 45-50 mm aortic

dilation

Class IV: Very high risk, pregnancy not recommended

- Severe MS

- Severe symptomatic AS

-PAH

- LVEF $<30 \%$, NYHA III-IV func-

tional class

-Prior PPCM with residual LV

dysfunction

- Uncorrected severe coarctation

-Marfan with $>45 \mathrm{~mm}$ aortic

dilation 
Table 2. (Continued)

CARPREG II

ZAHARA

Modified WHO

- Bicuspid with $>50 \mathrm{~mm}$ aortic dilation

\section{Preconception counseling}

the risk stratification of women without pre-existing cardiovascular disease, who are increasingly experiencing adverse cardiovascular events during pregnancy.

Obtaining preconception imaging requires that all cardiologists proactively ask women about their intentions surrounding pregnancy during all routine cardiovascular visits and ensuring that they have a plan for reliable contraception should pregnancy not be intended. Tools such as the One Key Question ${ }^{\circledR}$ of "Would you like to become pregnant in the next year" [32] can easily be incorporated into all cardiovascular visits among women of reproductive potential. Women with high-risk cardiovascular lesions should be referred to a center with cardio-obstetric expertise and undergo more extensive evaluation

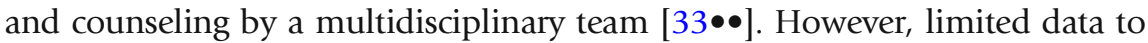
date suggest that the prevalence of preconception counseling is suboptimal even among women with mWHO 3 and 4 disease, highlighting the need for more routine counseling of women of reproductive age at all cardiovascular encounters [34].

Echocardiography is central to preconception counseling of women with known pre-existing valvular heart disease and any woman with a history of valvular prosthesis or native valve disease should ideally undergo echocardiographic imaging prior to conception. Lesion severity is incorporated into the major risk stratification tools (CARPREG II [30], mWHO [14], and ZAHARA [31]), with left-sided stenotic lesions and mechanical prostheses posing the highest risk to pregnant women. Women with high-risk lesions (particularly mitral stenosis) should be counseled that even if well compensated outside of pregnancy, given significant increases in heart rate, circulating volume, and cardiac output during pregnancy, left-sided stenotic lesions are high risk in the context of pregnancy and therefore merit intervention when possible prior to conception [33••]. Valve characteristics should be carefully imaged in the preconception setting in order to optimally guide interventional strategies when necessary. If possible, valve repair is preferable to bioprosthetic replacement, as the presence of a bioprosthesis still increases a woman's cardiovascular risk during pregnancy above women without structural heart disease, though is far preferable to untreated significant native valve disease [35] and can be subject to deterioration during pregnancy $[36,37]$. Mechanical prostheses should be 
avoided whenever possible in women who may desire future pregnancy due to their high-risk profile to both mother and fetus during pregnancy $[30 \bullet \bullet, 36]$, in large part mediated by the multitude of complicating factors surrounding anticoagulation during pregnancy.

Congenital heart disease

Women with pre-existing congenital heart disease should be followed at centers with expertise in adult congenital disease. Given the unique risk profile-especially of women with complex congenital disease-preconception echocardiograms are critical and should be obtained when counseling women regarding their risk during pregnancy. During pregnancy, these women should be followed by a multidisciplinary cardio-obstetric team inclusive of an adult congenital cardiologist and monitoring should include frequent echocardiography.

Women with severe systolic impairment prior to pregnancy (LVEF $<30 \%$ ) should be counseled regarding their very high risk and discouraged from pregnancy $[14 \bullet \bullet, 30 \bullet \bullet$. Notably, given that many women with cardiomyopathies are treated with medications that are contraindicated in the context of pregnancy, those wishing to consider pregnancy should have their LVEF, functional capacity, and contractile reserve reevaluated after cessation of contraindicated medications to ensure stability of LV function. Women with even mild LV dysfunction should be counseled regarding their elevated risk in the context of pregnancy and strain imaging should be considered in this evaluation as an early marker of systolic dysfunction $[14 \bullet \bullet, 30 \bullet \bullet$. Preconception, women with hypertrophic cardiomyopathy should also undergo echocardiography, with careful evaluation of the

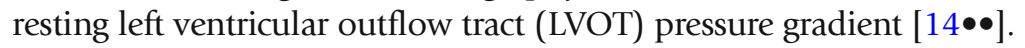

Women who received cardiotoxic chemotherapy or radiation

Echocardiography is central to the cardiovascular monitoring of patients receiving cardiotoxic chemotherapy. In particular, global longitudinal strain (GLS) is key in the monitoring of patients as a more sensitive means of detecting early systolic dysfunction as compared with LVEF alone. With advances in oncologic treatment and increasing maternal age, more female survivors of cancer are entering pregnancy and should undergo preconception evaluation. The Children's Oncology Group (COG) recommends preconception cardiovascular evaluation for women who have received $\geq 300 \mathrm{mg} / \mathrm{m}^{2}$ of cumulative anthracycline, $\geq 30$ Gy of chest radiation, combination chemotherapy and radiation, and who have already manifested arrhythmias or structural disease [38]. Women who have received cardiotoxic treatment (particularly anthracycline therapy) should undergo echocardiography preconception in order to assess for pre-existing systolic dysfunction [39], inclusive of strain imaging when possible. Those who 
have received chest radiation should also undergo preconception screening for valvular heart disease $[14 \bullet \bullet]$.

\section{Echocardiography in pregnant women with pre-existing cardio- vascular disease}

During pregnancy, overall guidelines are lacking with respect to standard intervals for routine re-imaging of women with pre-existing cardiovascular disease. Present available recommendations suggest imaging each trimester, though

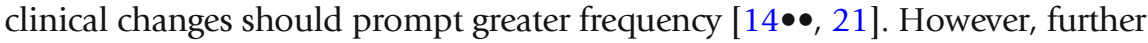
research is required to understand better how best to monitor women with cardiovascular disease during their pregnancies in the absence of clinical changes. For example, in the Standardized Outcomes in Reproductive Cardiovascular Care (STORCC) initiative in which women with pre-existing cardiovascular disease received echocardiograms preconception, second trimester, third trimester, and postpartum, only $12 \%$ of women were found to have significant echocardiographic changes during their pregnancy on routine monitoring [40]. Of the additional studies performed for clinical indications, 24\% resulted in a change in management decisions. Thus, further investigations are required to optimize routine monitoring strategies for women with pre-existing disease, including how best to incorporate echocardiography into routine monitoring. All women with pre-existing cardiovascular disease (and all fetuses with a firstdegree relative with structural heart disease or relevant disorder of Mendelian inheritance within their family) should be offered screening fetal echocardiography [41].

\section{Evaluation of acquired cardiovascular disease during pregnancy}

A large proportion of cardiovascular events occur de novo during pregnancy in women without known pre-existing CVD and echocardiography should therefore also be utilized as the first-line imaging modality of choice should a woman experience any concerning signs or symptoms of cardiovascular disease. While there is substantial overlap in the signs and symptoms of normal pregnancy and early cardiovascular disease, any woman presenting with chest pain, dyspnea at rest or with minimal exertion (especially when sudden in onset), paroxysmal nocturnal dyspnea, syncope, sustained palpitations, new systolic murmur (excluding flow murmurs), diastolic murmurs, persistent tachycardia $>100$ beats per minute, cyanosis or clubbing, an S4, pulmonary rales, elevated jugular venous pressure, or cyanosis/clubbing should be evaluated by a cardiologist and often imaged with echocardiography (Fig. 2).

\section{Hypertensive disorders of pregnancy}

Hypertensive disorders of pregnancy (HDP) are affecting an increasing number of women and are a leading cause of maternal morbidity and mortality 
- Chest pain

- Dyspnea at rest

- Paroxysmal nocturnal dyspnea

- Syncope

- Sustained palpitations

- Symptoms starting and progressively worsening $>20$ weeks gestation

- Diastolic murmur

- Heart rate $>100$ bpm

- Cyanosis or clubbing

- Rales

- S4 or Gallop

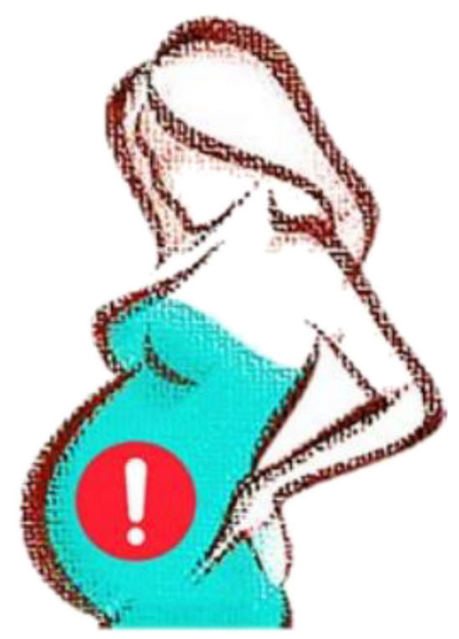

Fig. 2. Signs and symptoms that warrant further cardiovascular investigation in pregnancy. Image reproduced with permission from [42].

worldwide after cardiovascular disease. As assessed on a per-woman basis, HDP affect $15.3 \%$ of women, and preeclampsia occurs in $7.5 \%$ [43]. In contrast to chronic hypertension, HDP develops after 20 weeks of gestation with hypertension $\geq 140 / 90 \mathrm{mmHg}$. Gestational hypertension is defined as new onset hypertension alone while pre-eclampsia occurs when hypertension is associated with significant proteinuria or end-organ dysfunction. Women with chronic hypertension are at elevated risk for developing superimposed pre-eclampsia,

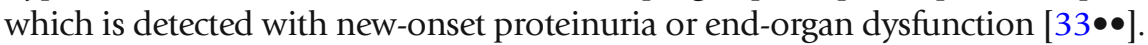
While the manifestations of HDP occur in late pregnancy or postpartum, the clinical syndrome begins with abnormal placentation and failure of normal trophoblast invasion and incomplete spiral artery remodeling [44]. Resulting placental hypoxia results in an increase in angiogenic markers, which result in endothelial dysfunction, vasoconstriction, and oxidative stress. Thus, in contrast to normal pregnancy, women with HDP experience an increase in vascular resistance, which results in adverse left ventricular remodeling with concentric-rather than normative eccentric-remodeling [44, 45]. In one study examining echocardiographic findings in the context of acute preeclampsia, right ventricular systolic pressure (RVSP), left atrial area, left ventricular wall thickness, and the mitral $\mathrm{E} / \mathrm{e}^{\prime}$ ratio were all significantly higher among women with preeclampsia ( $N=63$ cases) as compared to normotensive pregnant women $(N=36$ controls) [46]. However, when the absolute values are examined, they were not significantly elevated from a clinical perspective among women with acute preeclampsia (e.g., RVSP $31 \mathrm{mmHg} \pm 7.9$ vs $22.5 \mathrm{mmHg} \pm 6.1$ ) [47], and thus, further investigation is warranted into the acute cardiovascular effects of the disease process. Development of pulmonary edema among women with preeclampsia is often multifactorial with contributions from diastolic dysfunction, increased vascular permeability, volume retention from corticosteroid administration (in the context of fetal prematurity), and volume administration in the context of labor and delivery, which remains the mainstay of treatment. 
Furthermore, there is significant overlap between preeclampsia and peripartum cardiomyopathy [47-50], and thus, women with preeclampsia-especially those with dyspnea, volume overload, and evidence of pulmonary edema-may warrant investigation with echocardiography to assess for left ventricular systolic and diastolic function.

Beyond pregnancy, HDP are robustly associated with increased later-life risk of cardiovascular disease and are included in the most recent American Heart Association (AHA) lipid guidelines as a risk enhancing factor [51]. In addition to increasing a woman's risk of future coronary disease, however, they are further recognized to increase risk of heart failure, as well as valvular disease including aortic stenosis and mitral regurgitation [52]. While HDP are overall felt to increase risk through accelerated vascular aging, the specific mechanism of later-life valvular dysfunction is currently unknown and warrants further investigation. In addition, echocardiographic analyses of women performed a decade after HDP demonstrate evidence of adverse LV remodeling with increased left ventricular wall thickness and relative wall thickness as compared with women who experienced normotensive pregnancies [53]. Women who developed chronic hypertension following HDP represented the highest risk group, though women with HDP alone in the absence of chronic hypertension still demonstrated high risk of adverse remodeling. Given the recent emergence of these data, the manner in which women demonstrating evidence of adverse LV remodeling following HDP should be surveyed long term is a question that requires further investigation.

\section{Peripartum cardiomyopathy}

Peripartum cardiomyopathy (PPCM) is a rare but serious cardiac complication of pregnancy. The diagnosis is made when new onset cardiomyopathy (defined as an LVEF $<45 \%$ ) develops in late pregnancy or early postpartum [54]. It is often accompanied by left ventricular dilation, right ventricular dysfunction, pulmonary hypertension, biatrial enlargement, intracardiac thrombus, and functional valvular regurgitation. In addition to being central to the diagnosis, echocardiography provides prognostic information for patients with PPCM. The IPAC (Investigations of Pregnancy Associated Cardiomyopathy) study followed 100 women in North America with peripartum cardiomyopathy for 1 year after delivery [55]. In this group, severe impairment of left ventricular systolic function at baseline $($ LVEF $<0.30)$ and left ventricular dilation $($ LVEDD $>6.0 \mathrm{~cm})$ were both associated with lower LVEF at 12 months. The majority of women in this study experienced left ventricular recovery at 12 months. However, none of the women with both a baseline LVEF $<0.30$ and an LVEDD $\geq 6.0 \mathrm{~cm}$ experienced recovery of systolic function. In contrast, $91 \%$ of women with an initial LVEF $\geq 0.30$ and LVEDD $<6.0 \mathrm{~cm}$ recovered. After multivariable adjustment, race and LVEDD remained significant predictors of systolic recovery. Subgroup analyses further demonstrated significant association between baseline LVEF and LVEF at 1 year only in Black women $(p=0.005)$ and that Black race was independently associated with lower LVEF at 1 year. Thus, in essence, Black women were less likely to 
experience improvement of LVEF at 1 year as compared with non-Black women. In another cohort, African American women were nearly twice as likely to demonstrate persistent LV dysfunction as compared with nonAfrican American women (52 [43.0\%] vs 24 [24.2\%], $P=.004$ ), and, when they did recover, recovery took at twice as long (median, 265 vs 125.5 days; $P=.02)$ [56]. Right ventricular function at diagnosis has also been shown to be predictive of prognosis with impaired right ventricular function (RV fractional area change $<36 \%$ ) associating with higher rates of persistent $\mathrm{LV}$ dysfunction or adverse clinical events $(7.2$ (95\% CI, 5.1-58.6; $P<0.001)$ ) [57]. Analysis of strain patterns also shows a decrease in GLS in PPCM patients $[58,59]$, and the presence of these strain changes appear to be associated with worse cardiovascular outcomes, which include higher rates of LV assist device implantation, persistent LV dysfunction, and death. In analysis of patients within IPAC, GLS at presentation at a cutoff of $10.6 \%$ (absolute value) and global circumferential strain (GCS) at a cutoff of $10.1 \%$ were both associated with adverse clinical outcomes with a high sensitivity and specificity and were found to be additive to LVEF assessment alone [59]. At baseline, 6 months, and 12 months, global longitudinal strain values were significantly lower for Black women as compared with non-Black women.

Echocardiography is also central to counseling women with a history of PPCM with respect to risk with subsequent pregnancy. Multiple studies demonstrate that women with persistent left ventricular dysfunction are at highest risk and mortality can be as high as $50 \%$ in some series [60]. While in a single study, normalization of systolic function was found to be associated with a low risk of mortality in subsequent pregnancy (as compared with a reported $19 \%$ among women with persistent LV dysfunction), but the risk of clinical heart failure (21\%), decrement in LVEF $(21 \%)$, and durable LV dysfunction (14\%) remained significant [61]. Women with persistent LV dysfunction who enter a subsequent pregnancy experience heart failure (44\%), decrement in LVEF (25\%), and persistent LV function $(31 \%)$ at substantial rates.

Beyond LVEF, there is significant interest in how best to risk stratify patients desiring a future pregnancy, with some evidence supporting the utilization of stress echocardiography to evaluate contractile reserve [62]. In a small case series of pregnant women post-PPCM, none of the 9 women with adequate contractile reserve on exercise stress echo experienced PPCM recurrence [63]. More recently, there have been reports of uncomplicated pregnancies in women with contractile reserve using dobutamine stress echocardiography [20]. Whether strain imaging may provide additive prognostic value is of interest and merits further investigation.

\section{Aortopathies and pregnancy}

Aortic dissection occurs uncommonly during pregnancy and the postpartum period (5.5 cases per million pregnant women) but carries a high risk of mortality and occurs more commonly during pregnancy than in a comparable non-pregnant population ( 1.4 cases per million women) [64]. Among women younger than age 35 enrolled in the International 


\section{Coronary ischemia in pregnancy}

Registry of Acute Aortic Dissection (IRAD) registry, 19\% experienced dissections in the context of pregnancy [64] demonstrating the elevation in risk that pregnancy poses with respect to this cardiovascular complication [65]. Risk of dissection is greatest between 3 months of gestation and 3 months postpartum [64], with most postpartum dissections occurring in the first 2 weeks postpartum [65]. Women with Marfan syndrome, Loeys-Dietz, type 4 Ehlers-Danlos, Turner's syndrome, bicuspid aortopathies, and familial aortopathies represent the highest risk groups, though $47 \%$ of dissections occur in pregnant women who were not previously aware of an aortopathy until after their dissection [64, 66]. Transthoracic echocardiogram (TTE) is the preferred initial study for diagnosing and monitoring thoracic aortopathies in pregnancy. The frequency with which monitoring is recommended depends on underlying pathology but is generally monthly or bimonthly, with TTE serving as a powerful tool for surveillance when dilation is localized to the ascending aorta [67]. Sur-

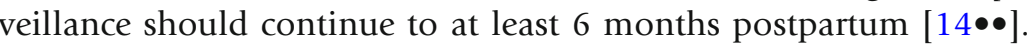

Ischemic heart disease is a relatively rare complication of pregnancy (occurring in between 2.8 and 8.1 per 100,000 deliveries) although the prevalence is expected to rise with advancing maternal age and increasing prevalence of obesity, hypertension, and diabetes [68, 69]. When it does occur, myocardial infarction during pregnancy is associated with an excess of both maternal and fetal mortality [70, 71]. In addition to atherosclerotic coronary artery disease which is believed to be responsible for approximately one-third of cases, pregnancy-associated myocardial infarction may occur due to spontaneous coronary artery dissection (SCAD), coronary embolus or in situ thrombus, and coronary vasospasm [69]. Women with a history of ischemic heart disease who desire pregnancy should undergo echocardiography to determine pre-pregnancy LVEF and assess for baseline

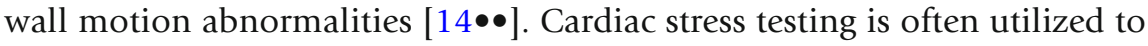
assess for burden of residual ischemia pre-pregnancy, and as such, stress echocardiography is a useful tool for assessment of LV function with stress $[14 \bullet \bullet, 72]$. During pregnancy, any woman presenting with an acute myocardial infarction should be treated with guideline directed therapy as in the non-pregnant population-including coronary angiography when indicated. However, in women presenting with chest pain in the absence of a clear acute coronary syndrome, TTE remains a readily accessible and safe additional diagnostic test to assess LV function, regional wall motion abnormalities, and non-ischemic findings which may be contributing to symptoms.

\section{Contemporary issues related to echocardiography in pregnancy}

Recent data from the Centers for Disease Control (CDC) in the USA examining 8207 pregnant women who tested positive for SARS-CoV2 found that after adjusting for age, medical comorbidities, race and 
ethnicity, pregnant women were significantly more likely to be admitted to the intensive care unit (with an adjusted risk ratio of 1.5; 95\% CI 1.2-1.8) and require mechanical ventilation (with an adjusted risk ratio of $1.7,95 \%$ CI 1.2-2.4) as compared to non-pregnant women. The risk of death however did not differ by pregnancy status (with an adjusted risk ratio of $0.9,95 \% \mathrm{CI}=0.5-1.5$ ) [73•]. As such, pregnant women appear to be at elevated risk for adverse outcomes in the context of COVID-19 infections.

Cardiomyopathy has been reported in case series of pregnant patients with severe COVID-19 [74, 75], and many experts have called for a lower threshold for use of echocardiography in clinically appropriate patients to allow for early detection of cardiac dysfunction in the context of COVID 19 [76]. The American College of Cardiology (ACC) Clinical Guidance for COVID-19 suggests that patients demonstrating heart failure signs/symptoms, arrhythmia, or have electrocardiographic changes should undergo echocardiography [77]. The evaluation of the right ventricle (RV) is of particular importance especially for acutely ill COVID-19 patients with suspected acute cor pulmonale. The use of echocardiography per local safety protocols, and with appropriate use of personal protective equipment (PPE), is especially highlighted by the ACC and supported by the American Society of Echocardiography (ASE) [78]. Because of its portability, echocardiography affords a clear advantage in imaging patients as it minimizes risk of virus transmission involved in having to move the patient. Hand-held point-of-care devices are increasingly favored given reduced risk of contamination of devices as compared to traditional machines.

In contrast to a global reduction in maternal mortality, the maternal mortality rate in the USA continues to increase, with a $150 \%$ increase from 1987 to 2016 (7.2 to 17.4 per 100,000 live births) [79]. Significant disparities exist within maternal outcomes in the USA, with Black women facing a 3-4× higher risk of pregnancy-related mortality as compared with White women [80]. While differences in social determinants of health contribute to these disparities, they do not entirely account for the differences in US maternal health between Black and non-Black women [81]. Beyond maternal mortality itself, HDP and PPCM are known to disproportionately affect Black women. $[56,82,83]$ Access to care during pregnancy and the postpartum period is often highlighted as a significant determinant of maternal health and most pregnancy-associated deaths are felt to be preventable [81]. This is critical to understand, especially in the context of research among non-pregnant populations, which have demonstrated that women, Black patients, Medicaid patients, and those of increasing age (by decade after age 60 ) are less likely to receive appropriate TTE surveillance for valvular disease [84]. A broader critique of echocardiographic use is that current studies used to define normative values do not to reflect the diversity of populations in the USA 
[85]. The ongoing COVID-19 pandemic has further illuminated the gaps and disparities that already existed in both the pregnant and non-pregnant populations. Data from the CDC [86] as well as the UK Obstetric Surveillance System [87] have demonstrated that as with the non-pregnant population, Black and Hispanic pregnant women have been disproportionately affected by COVID-19 infections during pregnancy.

\section{Areas for future research}

\section{Conclusion}

Though echocardiography is widely utilized in the clinical care of pregnant women with preexisting cardiovascular disease, further prospective studies are required to improve our understanding of best practices for its use in the context of pregnancy, including appropriate screening intervals for various cardiovascular conditions. This may be particularly true for the postpartum period during which women remain at elevated risk for adverse cardiovascular events but often do not receive routine screening or care. With advancements in strain imaging, further research is required to better understand the potential prognostic information that this technique may add to traditional function assessments alone. Finally, emerging echocardiographic data highlight the impact that cardiovascular diseases of pregnancy-particularly HDP-have on future adverse cardiovascular remodeling and further research is required to better understand these structural changes and their implications for the long-term cardiovascular health of women.

Pregnancy is characterized by significant hemodynamic and cardiovascular changes and as such is a period of elevated cardiovascular risk for women. Echocardiography can help define, risk-stratify, and monitor these changes throughout pregnancy and the postpartum period.

\section{Declarations}

\section{Conflict of Interest}

Henrietta A. Afari declares that she has no conflict of interest.

Esther F. Davis declares that she has no conflict of interest.

Amy A. Sarma declares that she has no conflict of interest.

\section{Human and Animal Rights and Informed Consent}

This article does not contain any studies with human or animal subjects performed by any of the authors. 


\section{References and Recommended Reading}

Papers of particular interest, published recently, have been highlighted as:

- Of importance

- Of major importance

1. Khan KS, Wojdyla D, Say L, Gulmezoglu AM, Van Look PF. WHO analysis of causes of maternal death: a systematic review. Lancet. 2006;367:1066-74. https://doi. org/10.1016/S0140-6736(06)68397-9.

2. Collier AY, Molina RL. Maternal mortality in the United States: updates on trends, causes, and solutions. Neoreviews. 2019;20(10):e561-74. https://doi.org/10. 1542/neo.20-10-e561.

3. Grandi SM, Filion KB, Yoon S, Ayele HT, Doyle CM, Hutcheon JA, et al. Cardiovascular disease-related morbidity and mortality in women with a history of pregnancy complications. Circulation. 2019;139:1069-79. https://doi.org/10.1161/ CIRCULATIONAHA.118.036748.

4. Chung E, Leinwand LA. Pregnancy as a cardiac stress model. Cardiovasc Res. 2014;101:561-70. https://doi. org/10.1093/cvr/cvu013.

5. Matthews TJ, Hamilton BE. Delayed childbearing: more women are having their first child later in life. NCHS Data Brief. 2009;21:1-8.

6. Mosca L, Benjamin EJ, Berra K, Bezanson JL, Dolor RJ, Lloyd-Jones DM, et al. American Heart Association. Effectiveness-based guidelines for the prevention of cardiovascular disease in women-2011 update: a guideline from the American Heart Association. J Am Coll Cardiol. 2011;57:1404-23. https://doi.org/10. 1016/j.jacc.2011.02.005.

7. Heemelaar S, Petrus A, Knight M, van den Akker T. Maternal mortality due to cardiac disease in low- and middle-income countries. Tropical Med Int Health. 2020;25:673-86. https://doi.org/10.1111/tmi.13386.

8. State of California, Department of Public Health, California Birth and Death Statistical Master files, 1999 2013. https://www.cmqcc.org/research/ca-pamrmaternal-mortality-review. Accessed February 18, 2021.

9. Center for Diseases Control and Prevention. Pregnancy-Related Deaths: Data from 14 U.S. Maternal Mortality Review Committees, 2008-2017. https:// www.cdc.gov/reproductivehealth/maternal-mortality/ erase-mm/mmr-data-brief.html\#table2. Accessed February 18, 2021.

10. Yucel E, DeFaria Yeh D. Pregnancy in women with congenital heart disease. Curr Treat Options Cardiovasc Med. 2017;19(9):73. https://doi.org/10. 1007/s11936-017-0572-0.

11. Canobbio MM, Warnes CA, Aboulhosn J, Connolly HM, Khanna A, Koos BJ, et al. Management of pregnancy in patients with complex congenital heart disease: a scientific statement for healthcare professionals from the American Heart Association. Circulation.

12. Halpern DG, Weinberg CR, Pinnelas R, Mehta-Lee S, Economy KE, Valente AM. Use of medication for cardiovascular disease during pregnancy: JACC state-of the-art review. J Am Coll Cardiol. 2019;73(4):457-76. https://doi.org/10.1016/j.jacc.2018.10.075.

13. Liu S, Elkayam U, Naqvi TZ. Echocardiography in pregnancy: part 1. Curr Cardiol Rep. 2016;18(9):92. https://doi.org/10.1007/s11886-016-0760-7.

14.• Regitz-Zagrosek V, Roos-Hesselink JW, Bauersachs J, Blomström-Lundqvist C, Cífková R, De Bonis M, et al. ESC guidelines for the management of cardiovascular diseases during pregnancy. Eur Heart J.

2018;39(34):3165-241. https://doi.org/10.1093/ eurheartj/ehy340

Comprehensive consensus statement from the European Society of Cardiology that includes guidelines on the diagnosis and management of cardiac disease in pregnancy.

15. Desai DK, Moodley J, Naidoo DP. Echocardiographic assessment of cardiovascular hemodynamics in normal pregnancy. Obstet Gynecol. 2004;104(1):20-9. https://doi.org/10.1097/01.AOG.0000128170.15161. $1 d$.

16. Siu S, Colman J. Heart disease and pregnancy. Heart. 2001;85(6):710-5. https://doi.org/10.1136/heart.85. 6.710 .

17. Pieper PG. Expected and unexpected cardiac problems during pregnancy. Neth Hear J. 2008;16(12):403-5. https://doi.org/10.1007/BF03086186.

18. American College of Obstetricians and Gynecologists (ACOG). Guidelines for Diagnostic Imaging During Pregnancy and Lactation. 2017. https://www.acog.org/ Clinical-Guidance-and-Publications/CommitteeOpinions/Committee-on-Obstetric-Practice/ Guidelines-for-Diagnostic-Imaging-During-Pregnancyand-Lactation?IsMobileSet=false. Accessed February 18,2021

19. Muskula PR, Main ML. Safety with echocardiographic contrast agents. Circ Cardiovasc Imaging. 2017;10:e005459. https://doi.org/10.1161/ CIRCIMAGING.116.005459.

20. Al Bannay R, Husain A, AlJufairi Z. Peripartum cardiomyopathy, what if your patient plans to reconceive? Clin Case Rep. 2017;5(6):753-6. https://doi.org/10. 1002/ccr3.935.

21. O'Kelly AC, Sharma G, Vaught AJ, Zakaria S. The use of echocardiography and advanced cardiac ultrasonography during pregnancy. Curr Treat Options Cardiovasc Med. 2019;21(11):71. https://doi.org/10.1007/ s11936-019-0785-5. 
22. Melchiorre K, Sharma R, Thilaganathan B. Cardiac structure and function in normal pregnancy. Curr Opin Obstet Gynecol. 2012;24:413-21. https://doi.org/10. 1097/GCO.0b013e328359826f.

23. Savu O, Jurcut R, Giusca S, van Mieghem T, Gussi I, Popescu B. Morphological and functional adaptation of the maternal heart during pregnancy. Circ Cardiovasc Imaging. 2012;5:289-97. https://doi.org/ 10.1161/CIRCIMAGING.111.970012.

24. Tso G, Lee J, Lui G, Trivedi H, Cohen M, Bernstein P, et al. Range of echocardiographic parameters during normal pregnancy. J Am Coll Cardiol. 2018;59(13 Supplement):E1301-8. https://doi.org/10.5530/jcdr. 2014.2.2.

25. Tsiaras S, Poppas A. Cardiac disease in pregnancy: value of echocardiography. Curr Cardiol Rep. 2010;12(3):250-6. https://doi.org/10.1007/s11886010-0106-9.

26. Steeds RP. Echocardiography: frontier imaging in cardiology. Br J Radiol. 2011;84(Spec Iss 3):S237-44. https://doi.org/10.1259/bjr/77730594.

27. Safi LM, Tsiaras SV. Update on Valvular heart disease in pregnancy. Curr Treat Options Cardiovasc Med. 2017;19(9):70. https://doi.org/10.1007/s11936-0170570-2.

28. Elkayam U, Bitar F. Valvular heart disease and pregnancy: part I: native valves. J Am Coll Cardiol. 2005;46(2):223-30. https://doi.org/10.1016/j.jacc. 2005.02.085.

29. Ristić A, Seferović P, Ljubić A, Jovanović I, Ristić G, Pankuweit $S$, et al. Pericardial disease in pregnancy. Herz. 2003;28:209-15. https://doi.org/10.1007/ s00059-003-2470-3.

30.• Silversides CK, Grewal J, Mason J, Sermer M, Kiess M, Rychel V, et al. Pregnancy outcomes in women with heart disease: the CARPREG II Study. J Am Coll Cardiol. 2018;71(21):2419-30. https://doi.org/10. 1016/j.jacc.2018.02.076

Pivotal CARPREG II study examining cardiac complications during pregnancy among women with preexisting cardiovascular disease and establishing a risk stratification index frequently used in clinical practice.

31. Kampman MA, Valente MA, van Melle JP, Balci A, Roos-Hesselink JW, Mulder BJ, et al. Cardiac adaption during pregnancy in women with congenital heart disease and healthy women. Heart. 2016;15(102(16)):1302-8. https://doi.org/10.1136/ heartjnl-2015-308946.

32. Power to decide: the campaign to prevent unwanted pregnancy. https://powertodecide.org/one-keyquestion Accessed February 18, 2021.

33.• Mehta LS, Warnes CA, Bradley E, Burton T, Economy K, Mehran R, et al. Cardiovascular considerations in caring for pregnant patients: a scientific statement from the American Heart Association. Circulation. 2020;141:e884-903. https://doi.org/10.1161/CIR. 0000000000000772

Scientific statement from the American Heart Association on the management of pregnant patients with cardiovascular diease.
34. Cauldwell M, Ghonim S, Uebing A, Swan L, Steer PJ, Gatzoulis M, et al. Preconception counseling, predicting risk and outcomes in women with $\mathrm{mWHO} 3$ and 4 heart disease. Int J Cardiol. 2017;234:76-80. https://doi.org/10.1016/j.ijcard.2017.02.003.

35. Badduke BR, Jamieson WRE, Miyagashima RT, Munro AI, Gerein AN, MacNab J, et al. Pregnancy and childbearing in a population with biologic valvular prostheses. J Thorac Cardiovasc Surg. 1991;102:179-86. https://doi.org/10.1016/S0022-5223(19)36549-3.

36. Van Hagen IM, Roos-Hesselink JW, Ruys TPE, Merz WM, Goland S, Gabriel H, et al. Pregnancy in women with a mechanical heart valve. Data of the European Society of Cardiology Registry of Pregnancy and Cardiac Disease (ROPAC). Circulation. 2015;132:132-42. https://doi.org/10.1161/CIRCULATIONAHA.115. 015242.

37. Jamieson WR, Munro AI, Miyagishima RT, Allen P, Burr LH, Tyers GFO. Carpentier-Edwards standard porcine bioprosthesis: clinical performance to seventeen years. Ann Thorac Surg. 1995;60:999-1006. https://doi.org/10.1016/0003-4975(95)00692-E.

38. Group CsO. Long-term follow-up guidelines for survivors of childhood, adolescent, and young adult cancers, version 4.0 Monrovia. Children's Oncology Group: CA; 2013. http://www.survivorshipguidelines. org/pdf/2018/COG_LTFU_Guidelines_v5.pdf. Accessed on February 18, 2021.

39. Celutkiene J, Pudil R, Lopez-Fernandez T, Grapsa J, Nihoyannopoulos P, Bergler-Klein J, et al. Role of cardiovascular imaging in cancer patients receiving cardiotoxic therapies: a position statement on behalf of the Heart Failure Association (HFA), the European Association of Cardiovascular Imaging (EACVI) and the Cardio-Oncology Council of the European Society of Cardiology (ESC). Eur Heart J Heart Fail. 2020;22:1504-24. https://doi.org/10.1002/ejhf.1957.

40. Valente AM, Landzberg MJ, Gauvreau K, Egidy-Assenza G, Barker N, Partington S, et al. Standardized outcomes in reproductive cardiovascular care: the STORCC initiative. Am Heart J. 2019;217:112-20. https://doi.org/ 10.1016/j.ahj.2019.07.015.

41. Donofrio MT, Moon-Grady AJ, Hornberger LK, Copel JA, Sklansky MS, Abuhamad A, et al. Diagnosis and treatment of fetal cardiac disease. Scientific Statement from the American Heart Association. Circulation. 2014;129:2183-242. https://doi.org/10.1161/01.cir. $0000437597.44550 .5 \mathrm{~d}$.

42. Lau E, O'Kelly A, Scott N. Pregnancy and cardiovascular disease. In: Aggarwal NR, Wood MJ, editors. Sex Differences in Cardiac Disease: Pathophysiology, Presentation, Diagnosis and Management. 1st ed. London: Elsevier; 2021. p. 390.

43. Garovic VD, White WM, Vaughan L, Saiki M, Parashuram S, Garcia-Valencia O, et al. Incidence and long-term outcomes of hypertensive disorders of pregnancy. JACC. 2020;75(18):2323-34. https://doi.org/ 10.1016/j.jacc.2020.03.028. 
44. Ives CW, Sinkey R, Rajapreyar I, Tita ATN, Oparil S. Preeclampsia-pathophysiology and clinical presentations: JACC state-of-the-art review. J Am Coll Cardiol. 2020;6(76(14)):1690-702. https://doi.org/10.1016/j. jacc.2020.08.014.

45. Ghossein-Doha C, Hooijschuur MCE, Spaanderman MEA. Pre-eclampsia: a twilight zone between health and cardiovascular disease? J Am Coll Cardiol. 2018;72(1):12-6. https://doi.org/10.1016/j.jacc.2018. 04.049 .

46. Vaught AJ, Kovell LC, Szymanski LM, Mayer SA, Seifert SM, Vaidya D, et al. Acute cardiac effects of severe preeclampsia. J Am Coll Cardiol. 2018;72(1):1-11. https://doi.org/10.1016/j.jacc.2018.04.048.

47. Behrens I, Basit S, Lykke JA, Ranthe MF, Wohlfahrt J, Bundgaard $\mathrm{H}$, et al. Hypertensive disorders of pregnancy and peripartum cardiomyopathy: a nationwide cohort study. PLoS One. 2019;14(2):e0211857. https://doi.org/10.1371/journal.pone.0211857.

48. Melchiorre K, Sutherland GR, Liberati M, Thilaganathan B. Preeclampsia is associated with persistent postpartum cardiovascular impairment. Hypertension. 2011;58(4):709-15. https://doi.org/10.1161/ HYPERTENSIONAHA.111.176537.

49. Honigberg MC, Riise HKR, Daltveit AK, Tell GS, Sulo $\mathrm{G}$, Igland J, et al. Heart failure in women with hypertensive disorders of pregnancy: insights from the cardiovascular disease in Norway project. Hypertension. 2020;76:1506-13. https://doi.org/10.1161/ HYPERTENSIONAHA.120.15654.

50. Melchiorre K, Sharma R, Thilaganathan B. Cardiovascular implications in preeclampsia: an overview. Circulation. 2014;130(8):703-14. https://doi.org/10. 1161/CIRCULATIONAHA.113.003664.

51. Arnett DK, Blumenthal RS, Albert MA, Buroker AB, Goldberger ZD, Hahn EJ, et al. ACC/AHA guideline on the primary prevention of cardiovascular disease: executive summary: a report of the American College of Cardiology/American Heart Association Task Force on Clinical Practice Guidelines. J Am Coll Cardiol. 2019;10(74(10)):1376-414. https://doi.org/10.1016/ j.jacc.2019.03.009.

52. Honigberg MC, Zekavat SM, Aragam K, Klarin D, Bhatt $\mathrm{DL}$, Scott NS, et al. Long-term cardiovascular risk in women with hypertension during pregnancy. J Am Coll Cardiol. 2019;74:2743-54. https://doi.org/10. 1016/j.jacc.2019.09.052.

53. Countouris ME, Villanueva FS, Berlacher KL, Cavalcante JL, Parks WT, Catov JM. Association of hypertensive disorders of pregnancy with left ventricular remodeling later in life. J Am Coll Cardiol. 2021;77(8):1057-68. https://doi.org/10.1016/j.jacc. 2020.12.051.

54. Davis MB, Arany Z, McNamara DM, et al. Peripartum cardiomyopathy: JACC state-of-the-art review. J Am Coll Cardiol. 2020;75(2):207-21. https://doi.org/10. 1016/j.jacc.2019.11.014.

55. McNamara DM, Elkayam U, Alharethi R, Damp J, Hsich E, Ewald G, et al. Clinical outcomes for peripartum cardiomyopathy in North America: results of the IPAC study (investigations of pregnancyassociated cardiomyopathy). J Am Coll Cardiol. 2015;66(8):905-14. https://doi.org/10.1016/j.jacc. 2015.06.1309.

56. Irizarry OC, Levine LD, Lewey J, Boyer T, Riss V, Elovitz $\mathrm{MA}$, et al. Comparison of clinical characteristics and outcomes of peripartum cardiomyopathy between African American and Non-African American women. JAMA Cardiol. 2017;2(11):1256-60. https://doi.org/ 10.1001/jamacardio.2017.3574.

57. Blauwet LA, Delgado-Montero A, Ryo K, Marek JJ, Alharethi R, Mather PJ, et al. Right ventricular function in peripartum cardiomyopathy at presentation is associated with subsequent left ventricular recovery and clinical outcomes. Circ Heart Fail. 2016;9(5). https:// doi.org/10.1161/CIRCHEARTFAILURE.115.002756.

58. Briasoulis A, Mocanu M, Marinescu K, Qaqi O, Palla M, Telila T, et al. Longitudinal systolic strain profiles and outcomes in peripartum cardiomyopathy. Echocardiography. 2016;33(9):1354-60. https://doi.org/10. 1111/echo.13277.

59. Sugahara M, Kagiyama N, Hasselberg NE, Blauwet LA, Briller J, Cooper L, et al. Global left ventricular strain at presentation is associated with subsequent recovery in patients with peripartum cardiomyopathy. J Am Soc Echocardiogr. 2019;32(12):1565-73. https://doi.org/ 10.1016/j.echo.2019.07.018.

60. Davis E, Yucel E. Risk stratification for subsequent pregnancy after prior peripartum cardiomyopathy. Curr Treat Options Cardio Med. 2021;23(2). https:// doi.org/10.1007/s11936-020-00882-2.

61. Elkayam U. Risk of subsequent pregnancy in women with a history of peripartum cardiomyopathy. J Am Coll Cardiol. 2014;64(15):1629-36. https://doi.org/ 10.1016/j.jacc.2014.07.961.

62. Dorbala S, Brozena S, Zeb S, Galatro K, Homel P, Ren JF, et al. Risk stratification of women with peripartum cardiomyopathy at initial presentation: a dobutamine stress echocardiography study. J Am Soc Echocardiogr. 2005;18(1):45-8. https://doi.org/10.1016/j.echo. 2004.08.027.

63. Fett JD, Fristoe KL, Welsh SN. Risk of heart failure relapse in subsequent pregnancy among peripartum cardiomyopathy mothers. Int J Gynaecol Obstet. 2010;109(1):34-6. https://doi.org/10.1016/j.ijgo. 2009.10.011.

64. Kamel H, Roman MJ, Pitcher A, Devereux RB. Pregnancy and the risk of aortic dissection or rupture: a cohort-crossover analysis. Circulation. 2016;134(7):527-33. https://doi.org/10.1161/ CIRCULATIONAHA.116.021594.

65. Braverman AC, Mittauer E, Harris KM, Evangelista A, Pyeritz RE, Brinster D, et al. Clinical features and outcomes of pregnancy-related acute aortic dissection. JAMA Cardiol. 2021;6(1):58-66. https://doi.org/10. 1001/jamacardio.2020.4876. 
66. Smok DA. Aortopathy in pregnancy. Semin Perinatol. 2014;38(5):295-303. https://doi.org/10.1053/j. semperi.2014.04.019.

67. Hiratzka LF, Bakris GL, Beckman JA, Bersin RM, Carr VF, Casey DE Jr, et al. ACCF/AHA/AATS/ACR/ASA/ SCA/SCAI/SIR/STS/SVM guidelines for the diagnosis and management of patients with thoracic aortic disease: executive summary. A report of the American College of Cardiology Foundation/American Heart Association Task Force on Practice Guidelines, American Association for Thoracic Surgery, American College of Radiology, American Stroke Association, Society of Cardiovascular Anesthesiologists, Society for Cardiovascular Angiography and Interventions, Society of Interventional Radiology, Society of Thoracic Surgeons, and Society for Vascular Medicine. Catheter Cardiovasc Interv. 2010;76(2):E43-86. https://doi.org/10.1002/ ccd.22537.

68. Lameijer H, Kampman M, Oudijk M, Pieper PG. Ischaemic heart disease during pregnancy or post-partum: systematic review and case series. Neth Hear J. 2015;23:249-57. https://doi.org/10.1007/s12471015-0677-6.

69. Tweet MS, Lewey J, Smilowitz NR, Rose CH, PJM B. Pregnancy-associated myocardial infarction: prevalence, causes, and interventional management. Circ Cardiovasc Interv. 2020. https://doi.org/10.1161/ CIRCINTERVENTIONS.120.008687.

70. Smilowitz NR, Gupta N, Guo Y, Zhong J, Weinberg CR, Reynolds HR, et al. Acute myocardial infarction during pregnancy and the puerperium in the United States. Mayo Clin Proc. 2018;93(10):1404-14. https://doi. org/10.1016/j.mayocp.2018.04.019.

71. Elkayam U, Jalnapurkar S, Barakkat MN, Kealey AJ, Mehra A, Roth A. Pregnancy-associated acute myocardial infarction: a review of contemporary experience in 150 cases between 2006 and 2011. Circulation. 2014;129(16):1695-702. https://doi.org/10.1161/ CIRCULATIONAHA.113.002054.

72. Pellikka PA, Arruda-Olson A, Chaudhry FA, Chen MH, Marshall JE, Porter TR, et al. Guidelines for performance, interpretation, and application of stress echocardiography in ischemic heart disease: from the American Society of Echocardiography. J Am Soc Echocardiogr. 2020;33(1):1-41.e8. https://doi.org/10. 1016/j.echo.2019.07.001.

73.• Ellington S, Strid P, Tong VT, Woodworth K, Galang $\mathrm{RR}$, Zambrano LD, et al. Characteristics of women of reproductive age with laboratory-confirmed SARS$\mathrm{CoV}-2$ infection by pregnancy status - United States, January 22-June 7, 2020. MMWR Morb Mortal Wkly Rep. 2020;69:769-75. https://doi.org/10.15585/ mmwr.mm6925a1

This is a comprehensive, nationwide periodic analytic report published by the US Center for Disease Control and Prevention (CDC) on COVID-19 cases among pregnant women in the USA.

74. PJ, Attri PK, Farooqui W. Takotsubo cardiomyopathy in early term pregnancy: a rare cardiac complication of
SARS-CoV-2 infection. BMJ Case Rep CP. 2020;13:e239104. https://doi.org/10.1136/bcr-2020239104.

75. Juusela A, Nazir M, Gimovsky M. Two cases of COVID19 related cardiomyopathy in pregnancy. Am J Obstet Gynecol MFM. 2020;2(2) supplement. https://doi.org/ 10.1016/j.ajogmf.2020.100113.

76. Ryan GA, Purandare NC, McAuliffe FM, Hod M, Purandare CN. Clinical update on COVID-19 in pregnancy: a review article. J Obstet Gynaecol Res. 2020;46(8):1235-45. https://doi.org/10.1111/jog. 14321.

77. Maddox TM, Webster SE, Bozkurt B, ACC Science and Quality Committee. COVID-19 Clinical Guidance for the Cardiovascular Care Team. https://www.acc.org//-/ media/Non-Clinical/Files-PDFs-Excel-MS-Word-etc/ 2020/02/S20028-ACC-Clinical-Bulletin-Coronavirus. pdf. Accessed Jan 1, 2021.

78. Kirkpatrick JN, Mitchell C, Taub C, Kort S, Hung J, Swaminathan M. ASE statement on protection of patients and echocardiography service providers during the 2019 novel coronavirus outbreak. J Am Coll Cardiol. 2020;75(23):3078-84. https://doi.org/10. 1016/j.jacc.2020.04.002.

79. Center for Disease Control and Prevention. Pregnancyrelated deaths. https://www.cdc.gov/ reproductivehealth/maternalinfanthealth/pregnancyrelatedmortality.htm. Accessed March 2, 2021.

80. Howell EA. Reducing disparities in severe maternal morbidity and mortality. Clin Obstet Gynecol. 2018;61:387-99 10.1097.GRF.

81. Bond RM, Gaither K, Nasser SA, Albert MA, Ferdinand KC, Njoroge JN, Parapid B, Hayes SN, Pegus C, Sogade B, Grodzinsky A, Watson KE, McCullough CA, Ofili E, on behalf of the Association of Black Cardiologists Working agenda for Black mothers. A position paper from the association of Black cardiologists on solutions to improving Black maternal health. Circulation Cardiovasc Qual Outcomes 2021;14:e007643. https:// doi.org/10.1161/CIRCOUTCOMES.120.007643.

82. Kao DP, Hsich E, Lindenfeld J. Characteristics, adverse events, and racial differences among delivering mothers with peripartum cardiomyopathy. JACC Heart Fail. 2013;1(5):409-16. https://doi.org/10.1016/j.jchf. 2013.04.011.

83. Creanga AA, Berg CJ, Syverson C, Kristi S, Bruce CF, Callaghan WM. Race, ethnicity, and nativity differentials in pregnancy-related mortality in the United States: 1993-2006. Obstet Gynecol. 2012;120(2 Pt 1):261-8. https://doi.org/10.1097/AOG. 0b013e31825cb87a.

84. Tanguturi VK, Bhambhani V, Picard MH, Armstrong K, Wasfy JH. Echocardiographic surveillance of valvular heart disease in different sociodemographic groups. JACC Cardiovasc Imaging. 2019;12:751-2. https://doi. org/10.1016/j.jcmg.2018.05.025.

85. Asch FM, Banchs J, Price R, Rigolin V, Thomas JD, Weissman NJ, et al. Need for a global definition of normative echo values-rationale and design of the 
World Alliance of Societies of Echocardiography Normal Values Study (WASE). J Am Soc Echocardiogr. 2019;32:157-162.e2. https://doi.org/10.1016/j.echo. 2018.10.006.

86. Delahoy MJ, Whitaker M, O'Halloran A, Chai SJ, Kirley PD, Alden N, et al. Characteristics and maternal and birth outcomes of hospitalized pregnant women with laboratory-confirmed COVID-19 - COVID-NET, 13 States, March 1-August 22, 2020. MMWR Morb Mortal Wkly Rep. 2020;69(38):1347-54. https://doi.org/10. 15585/mmwr.mm6938e1.

87. Knight M, Bunch K, Vousden N, Morris E, Simpson N, Gale C, et al. Characteristics and outcomes of pregnant women admitted to hospital with confirmed SARSCoV-2 infection in UK: national population based cohort study. BMJ. 2020;369:m2107. https://doi.org/10. 1136/bmj.m2107.

\section{Publisher's Note}

Springer Nature remains neutral with regard to jurisdictional claims in published maps and institutional affiliations. 